Microstructural modifications in tungsten induced by high flux plasma exposure: TEM examination

This content has been downloaded from IOPscience. Please scroll down to see the full text. 2016 Phys. Scr. 2016014030

(http://iopscience.iop.org/1402-4896/2016/T167/014030)

View the table of contents for this issue, or go to the journal homepage for more

Download details:

IP Address: 157.193.64.83

This content was downloaded on 08/05/2017 at 14:17

Please note that terms and conditions apply.

You may also be interested in:

Numerical analysis of TDS spectra under high and low flux plasma exposure conditions P Grigorev, L Buzi, A Bakaeva et al.

Synergy of plastic deformation and gas retention in tungsten

D. Terentyev, G. De Temmerman, B. Minov et al.

Sub-surface structures of ITER-grade W (Japan) and re-crystallized W after ITER-similar low-energy and high-flux $D$ plasma loadings

S Lindig, M Balden, V Kh Alimov et al.

Deuterium retention in various toughened, fine-grained recrystallized tungsten materials under different irradiation conditions M Oya, H T Lee, Y Ohtsuka et al.

Blister bursting and deuterium bursting release from tungsten W.M. Shu, E. Wakai and T. Yamanishi

Surface morphology and deuterium retention in tungsten exposed to low-energy, high flux pure and helium-seeded deuterium plasmas

V Kh Alimov, W M Shu, J Roth et al.

Surface morphology and deuterium retention of tungsten after low- and high-flux deuterium plasma exposure

M.H.J. 't Hoen, M. Balden, A. Manhard et al.

Mitigated blistering and deuterium retention in tungsten exposed to high-flux deuterium-neon mixed plasmas

L. Cheng, G. De Temmerman, T.W. Morgan et al. 


\title{
Microstructural modifications in tungsten induced by high flux plasma exposure: TEM examination
}

\author{
A Dubinko $^{1,2}$, A Bakaeva ${ }^{1,2}$, M Hernández-Mayoral $^{3}$, D Terentyev ${ }^{1}$, \\ G De Temmerman ${ }^{4}$ and J-M Noterdaeme ${ }^{2}$ \\ ${ }^{1}$ Nuclear Materials Science Institute, SCK • CEN, B-2400 Mol, Belgium \\ ${ }^{2}$ Department of Applied Physics, Ghent University, B-9000 Ghent, Belgium \\ ${ }^{3}$ Division of Materials, CIEMAT, E-28040 Madrid, Spain \\ ${ }^{4}$ ITER Organization, CS 90 046, F-13067 St Paul Lez Durance Cedex, France \\ E-mail: adubinko@sckcen.be
}

Received 22 May 2015, revised 13 October 2015

Accepted for publication 6 November 2015

Published 13 January 2016

\begin{abstract}
We have performed microstructural characterization using transmission electron microscopy (TEM) techniques to reveal nanometric features in the sub-surface region of tungsten samples exposed to high flux, low energy deuterium plasma. TEM examination revealed formation of a dense dislocation network and dislocation tangles, overall resulting in a strong increase in the dislocation density by at least one order of magnitude as compared to the initial one. Plasmainduced dislocation microstructure vanishes beyond a depth of about $10 \mu \mathrm{m}$ from the top of the exposed surface where the dislocation density and its morphology becomes comparable to the reference microstructure. Interstitial edge dislocation loops with Burgers vector $a_{0} / 2\langle 111\rangle$ and $a_{0}\langle 100\rangle$ were regularly observed within $6 \mu \mathrm{m}$ of the sub-surface region of the exposed samples, but absent in the reference material. The presence of these loops points to a co-existence of nanometric $D$ bubbles, growing by loop punching mechanism, and sub-micron deuterium flakes, resulting in the formation of surface blisters, also observed here by scanning electron microscopy.
\end{abstract}

S Online supplementary data available from stacks.iop.org/PSTOP/T167/014030/mmedia

Keywords: tungsten, high flux plasma, dislocations

(Some figures may appear in colour only in the online journal)

\section{Introduction}

Tungsten (W) is the divertor material in ITER and also a candidate for the first wall material in DEMO. Mechanical and microstructural properties of the tungsten surface and the micrometric sub-surface region play a crucial role in its performance as armor material protecting functional components from the plasma heat (see recent review [1]). Due to technological constraints, the confinement of plasma in the ITER chamber is a complicated process and in certain operational modes oscillations in plasma stability will inevitably cause so-called edge localized modes (ELMs). The latter generate heat shocks within a very short period of time (ms) and appear with a frequency of several $\mathrm{Hz}$, hence exposing the sub-surface region to a cyclic load, subsequently leading to the nucleation of micro-cracks on the surface and their propagation towards the bulk [2]. Therefore, understanding of the evolution of mechanical properties of the sub-surface region is important for assessment of conditions favoring crack nucleation under relevant plasma exposure conditions.

Typical measurements done by nuclear reaction analysis (NRA) show that concentration of retained $D$ sharply decreases within first several $\mu \mathrm{m}$ (see e.g. [3-6]). However, the resolution of NRA does not allow probing deeper than $10 \mu \mathrm{m}$. Alternative measurements by secondary ion mass spectroscopy as well as comparison of integral retention 
Table 1. Impurity content of the double forged tungsten.

\begin{tabular}{llllllllllllllll}
\hline Impurities & $\mathrm{Ag}$ & $\mathrm{Ba}$ & $\mathrm{Co}$ & $\mathrm{Fe}$ & $\mathrm{Mn}$ & $\mathrm{Ni}$ & $\mathrm{Ti}$ & $\mathrm{Mo}$ & $\mathrm{Co}$ & $\mathrm{O}$ & $\mathrm{Si}$ & $\mathrm{Al}$ & $\mathrm{Ca}$ & $\mathrm{Cr}$ & $\mathrm{K}$ \\
$\mu \mathrm{g} \mathrm{g}^{-1}$ & 10 & 5 & 10 & 30 & 5 & 5 & 5 & 100 & 30 & 20 & 20 & 15 & 5 & 20 & 10 \\
Impurities & $\mathrm{Na}$ & $\mathrm{Pb}$ & $\mathrm{Zn}$ & $\mathrm{H}$ & $\mathrm{Pb}$ & $\mathrm{As}$ & $\mathrm{Cd}$ & $\mathrm{Cu}$ & $\mathrm{Mg}$ & $\mathrm{Nb}$ & $\mathrm{Ta}$ & $\mathrm{Zr}$ & $\mathrm{N}$ & $\mathrm{S}$ & \\
$\mu \mathrm{g} \mathrm{g}^{-1}$ & 10 & 5 & 5 & 5 & 20 & 5 & 5 & 10 & 5 & 10 & 20 & 5 & 5 & 5 & \\
\hline
\end{tabular}

measured by NRA and TDS suggest that deposition of $D$ can be divided into three zones: (i) the near-surface layer (up to a depth of $0.2-0.5 \mu \mathrm{m}$ depending on ion energy), (ii) the subsurface layer (up to several $\mu \mathrm{m})$, and (iii) the bulk $(>5 \mu \mathrm{m}$ ) $[4,7]$. The bulk retention component depends strongly on the exposure temperature and fluence, and for high temperature exposures the $D$ permeation can reach mm depth $[4,9,10]$. Also deep microstructural modification is reported in [11]. In addition, a computational assessment of $D$ retention by TMAP when compared with experimental TDS spectra also suggests the existence of retention deeper than $10 \mu \mathrm{m}$ (see e.g. [8]). However, the bulk retention in the high flux exposure (flux $>10^{22}$ ion $\mathrm{m}^{-2} \mathrm{~s}^{-1}$ ) up to $600 \mathrm{~K}$ represents a minor part of the integral retention, while most of $D$ is trapped within first several $\mu \mathrm{m}$.

Due to the strongly heterogeneous depth distribution mentioned above, the application of conventional mechanical testing procedures combined with microscopy examination is problematic. The $\mu \mathrm{m}$-scale depth is even smaller than a typical grain size of commercial tungsten, thus a large amount of the permeated $D$ is captured within the first subgrain, where its accumulation on interfaces results in the formation of cavities. Consequently, the cracks start to grow from those cavities, well observed by scanning electron microscopy (SEM). In case of recrystallized and large grain size material, the formation of cavities deeper than several micrometers was also observed [12]. However, besides the SEM-visible cavities, a significant concentration of $D$ is present in nanometric bubbles, formed as a result of plasma exposure and located within first several micrometers, as was recently reported by direct transmission electron microscopy (TEM) observations [13]. Those numerous bubbles may suppress dislocation slip, which mediates plasticity, and therefore disable the mechanisms allowing a release of thermal stresses induced by the ELMs. Hence, microstructural characterization of defects that are 'invisible' to the conventional surface analysis techniques is needed for further progress in assessment of the combined effects of plasma exposure and heat cycling loads.

Here, we perform an in-depth microstructural characterization using TEM techniques to reveal nanometric features in the sub-surface region of tungsten samples exposed to high flux low energy deuterium plasma. This work is a continuation of our recent study addressing the role played by heavy plastic deformation on $D$ retention and surface microstructure evolution [13-15]. Those works have demonstrated that plastically induced dislocation network enhances deuterium retention and amplifies the release stage around 450-600 K. Here, we provide the microstructural characterizatization of nano- and micro-scale defects that appeared as a result of plasma exposure.

\section{Experimental procedure and reference microstructure}

The investigated samples were cut from a double forged bar of tungsten of $99.99 \%$ purity, supplied by PLANSEE AG, Austria. The main impurities, as reported by the manufacturer, are listed in table 1 . The production route, initial microstructure and nominal mechanical properties of these materials were characterized previously in [16, 17]. The double hot forging was followed by a thermal stress relief treatment at $1270 \mathrm{~K}$ and annealing at $1870 \mathrm{~K}$ for $1 \mathrm{~h}$. The annealing made the shape of grains more uniform and reduced the dislocation density down to about $(2-8) \times 10^{12} \mathrm{~m}^{-2}$, as measured by TEM techniques. SEM and EBSD characterization revealed that a typical grain size was in the range $50-150 \mu \mathrm{m}$, and subgrains (mainly connected by low angle grain boundary interfaces) of size $2.5-5 \mu \mathrm{m}$ were present.

To produce samples with heavy but controlled plastic deformation, we fabricated macro flat tensile samples with gauge sections of $60 \times 12 \times 1.1 \mathrm{~mm}$. Then, six $10 \times 10 \times 1 \mathrm{~mm}$ samples were cut from the gauge sections and used for the plasma exposure. Also several $10 \times 3 \times 1 \mathrm{~mm}$ samples were cut at the middle of the gauge sections for TEM examination after the tensile test. The tests were conducted in air at $870 \mathrm{~K}$ applying the deformation rate of $0.2 \mathrm{~mm} \mathrm{~min}^{-1}$ which corresponds to a strain rate of $2.2 \times 10^{-4} \mathrm{~s}^{-1}$ min to reach $20 \%$ deformation, which is close to the ultimate tensile strength for this $\mathrm{W}$ grade. Oxidation at $870 \mathrm{~K}$ within the time of the tensile test was not significant and the top surface (i.e., several microns) was removed during the standard procedure of the sample preparation.

After the plastic deformation, individual dislocations and large dislocation tangles (with a significant presence of edge component) become apparent. Also regions with dense dislocation pile-ups formed next to the grain boundary interfaces were regularly seen. The average dislocation density was found to be $6.5 \times 10^{13} \mathrm{~m}^{-2}$, as measured following the method used in [18]. EBSD analysis revealed that the grain size did not change after the applied plastic deformation.

Exposures to deuterium plasma were performed at the linear plasma generator Pilot-PSI [19, 20], which delivers high-density, low-temperature plasmas mimicking the 'subdisplacement threshold' plasma wall interaction conditions expected in the ITER divertor. In this experiment, the energy of deuterium ions was $\sim 50 \mathrm{eV}$ (controlled by negatively biasing the target), while energies in excess of $900 \mathrm{eV}$ are required to initiate atomic displacement in W [21]. Although the plasma beam was non-uniform (full width at half maximum, FWHM, $\sim 10 \mathrm{~mm}$ ), the relatively small sample surface ensured a small temperature gradient. For the samples studied 


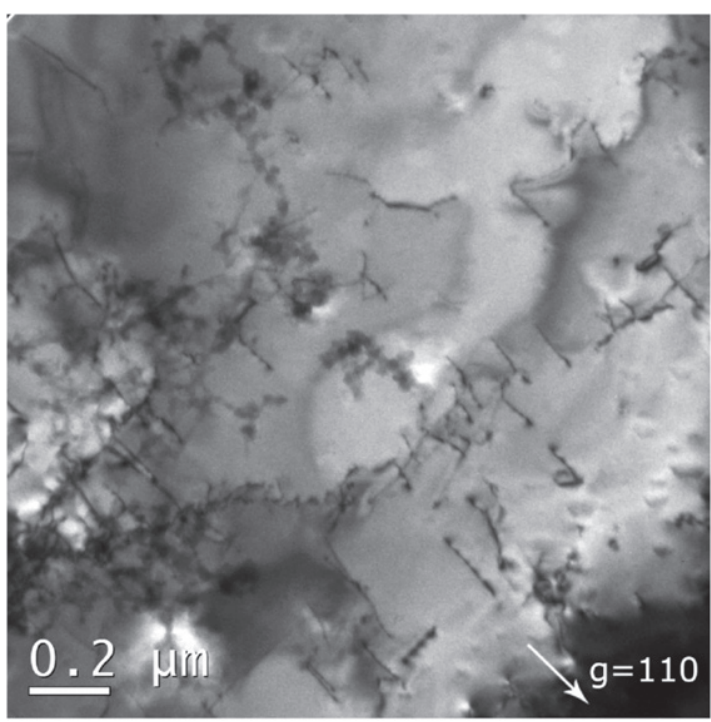

a)

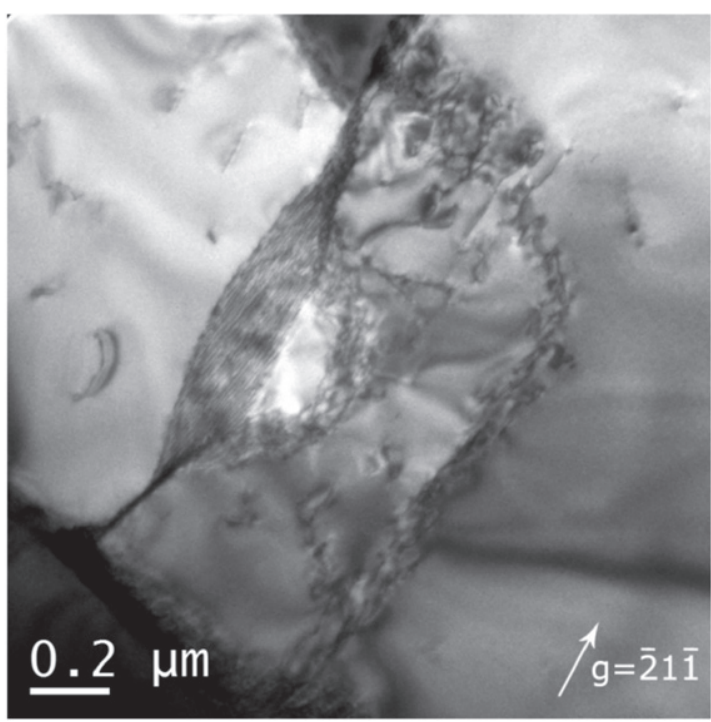

b)

Figure 1. TEM micrograph of a typical microstructure of $\mathrm{W}$ deformed to 20\%; (a) grain with homogeneous dislocation distribution; (b) grain exhibiting an inhomogeneous dislocation distribution with a dense pile-up formed in a front of subgrain boundary interface.

here, the temperature across the surface during the exposure was $620 \pm 10 \mathrm{~K}$, as measured and confirmed by an infra-red camera (FLIR A645 sc). The maximum particle flux in the center of the sample was close to $1.0 \times 10^{24} \mathrm{D} \mathrm{m}^{-2} \mathrm{~s}^{-1}$. The flux was calculated from the plasma electron density and electron temperature, as measured by Thomson scattering [22] at a distance of $\sim 25 \mathrm{~mm}$ upstream from the plasmafacing surface. As-deformed samples were exposed to a fluence of $F=5 \times 10^{25} \mathrm{D} \mathrm{m}^{-2}$, which corresponds to the exposure time of $70 \mathrm{~s}$, performed in one continuous discharge.

\section{Results}

The initial microstructure in terms of dislocation density and grain size was characterized by TEM and EBSD techniques. As mentioned in section 2, the measurements performed in the as-deformed material revealed the dislocation density in a range of $(5-7) \times 10^{13} \mathrm{~m}^{-2}$. The grain size was about 50-150 $\mu \mathrm{m}$. TEM observations showed the dislocation lines to be nearly ubiquitously present within grain interiors. However, near the grain boundary interfaces dislocation pileups were regularly observed. These features are demonstrated in figure 1.

In order to examine the microstructure of the surface layer of the exposed samples by TEM techniques, a back-side electrochemical polishing method was utilized. The top surface of the sample was mirror-finished before the exposure. TEM observations, made in the immediate sub-surface region (corresponds to zero depth in figure 3), showed a significant increase in dislocation density and their strongly inhomogeneous spatial distribution as well as dense dislocation networks, as presented in figure 2(a). The computed dislocation density was found to be more than by a factor of two higher in the first sub-surface region of the exposed sample as compared to the dislocation density in the bulk. In some regions, the dislocation density in tangles and networks was seen to reach $10^{15} \mathrm{~m}^{-2}$. However, the surface of those regions was rather small (typically $0.3 \times 0.3 \mu \mathrm{m}$ ) as compared to the sub-grain size and therefore we did not include this estimate in the statistical analysis. Unlike in the case of the nonexposed sample, the formation of dislocation tangles and pileups was no longer correlated with the presence of nearby subgrains.

To study a change of microstructure depending on a distance from the top of the exposed surface, the following methodology was used: back-side electrochemical polishing was applied to retain the exposed surface and was followed by consecutive polishing from both sides for 2,5 and $10 \mathrm{~s}$ to remove approximately $2.5,6$ and $12.5 \mu \mathrm{m}$ of the exposed surface layer. The typical appearance of dislocations at the studied depths is shown in figures 2(b)-(d) and the calculated dislocation density is presented in figure 3 . Due to a variation of the dislocation density from one region to another, we provide lower and upper bounds, in addition to the mean value. The origin of the variation of dislocation density is related to the variation in grain size as well as to the orientation of the grain. Figure 3 reveals that the dislocation density decreases as the surface region is removed, reaching the value found in the unexposed sample at $12.5 \mu \mathrm{m}$ below the exposed surface of the sample.

While inspecting the dislocation microstructure, dislocation loops with 'coffee bean' and 'dot-like' contrasts were also regularly observed within $6 \mu \mathrm{m}$ depth, as shown in figures 2(e), (f). The size of dislocation loops varied in a range $10-35 \mathrm{~nm}$, and their density could be approximately estimated as $10^{19} \mathrm{~m}^{-3}$. Analysis of $\mathbf{g} \cdot \mathbf{b}$ and habit plane revealed that these loops were of the edge type and interstitial in nature. Identification of the Burgers vectors showed that both $a_{0} /$ $2\langle 111\rangle$ and $a_{0}\langle 100\rangle$ loops were present. 


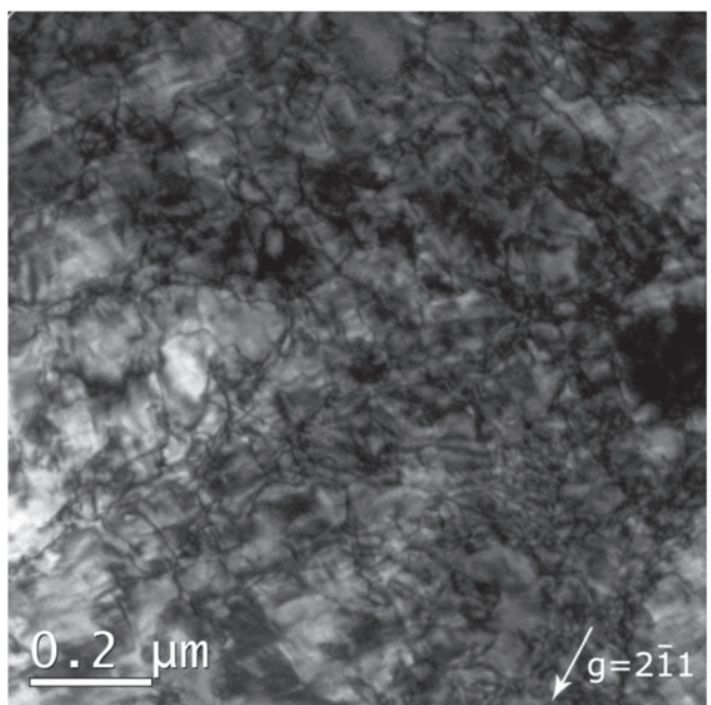

a)

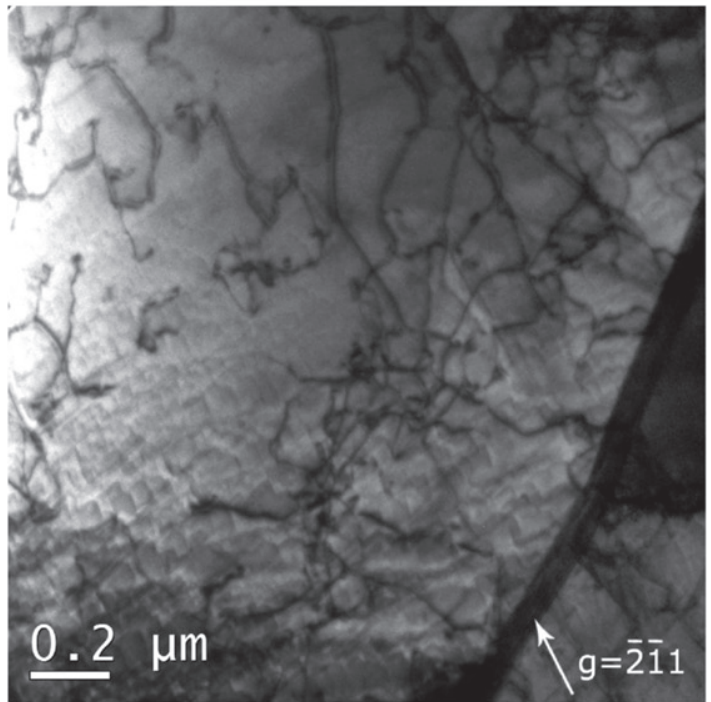

c)

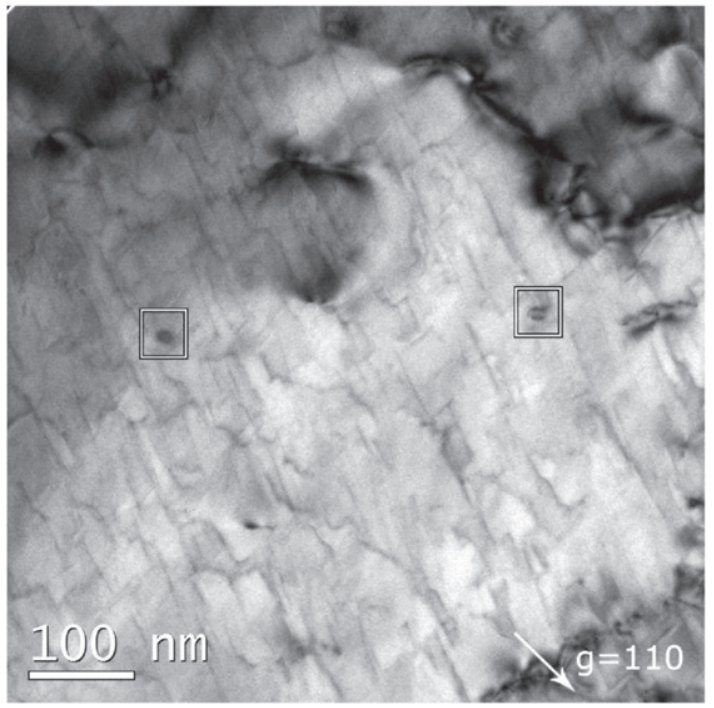

e)

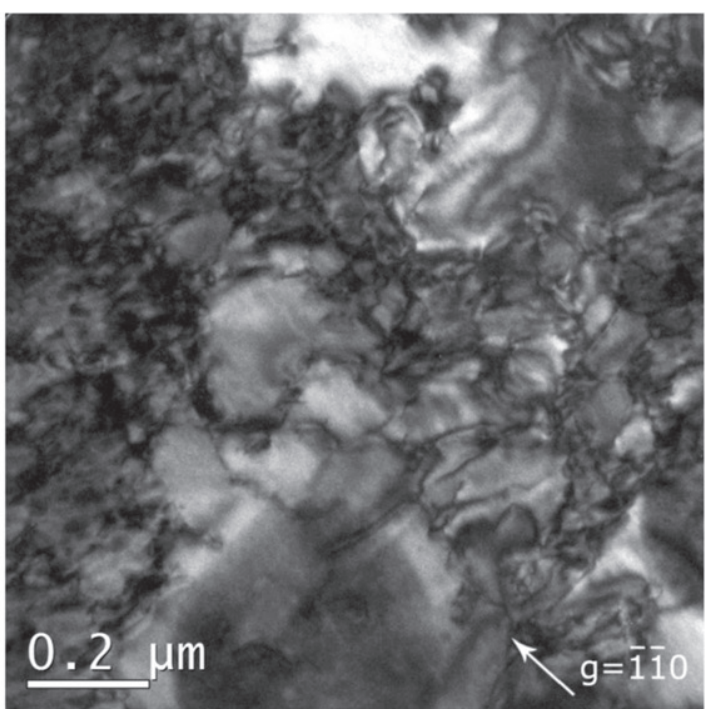

b)

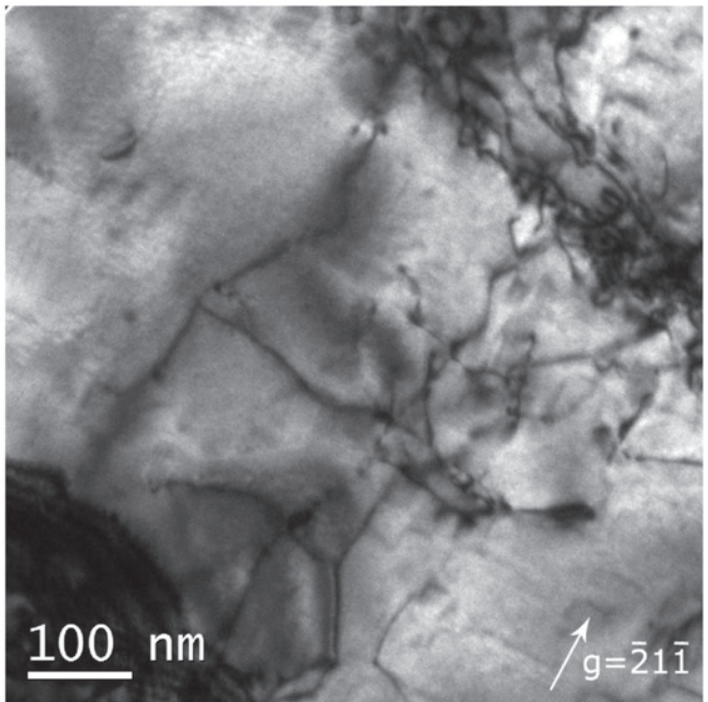

d)

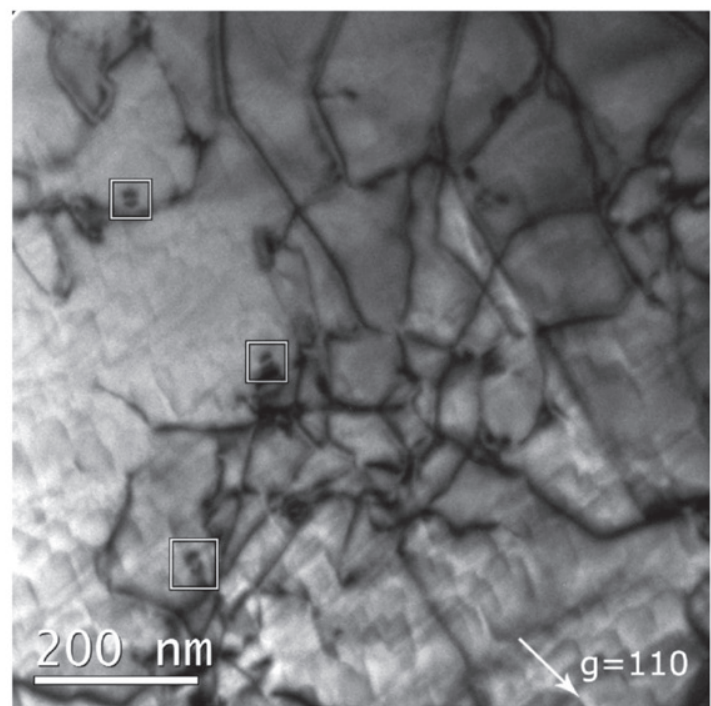

f)

Figure 2. TEM micrographs showing change in dislocation density with removal of the exposed surface: (a) at the exposed surface, (b) $2.5 \mu \mathrm{m}$ removed, (c) $6 \mu \mathrm{m}$ removed, (d) $12.5 \mu \mathrm{m}$ removed. Figures (e) and (f) demonstrate the dislocation loops observed within $6 \mu \mathrm{m}$ depth from the exposed surface. 


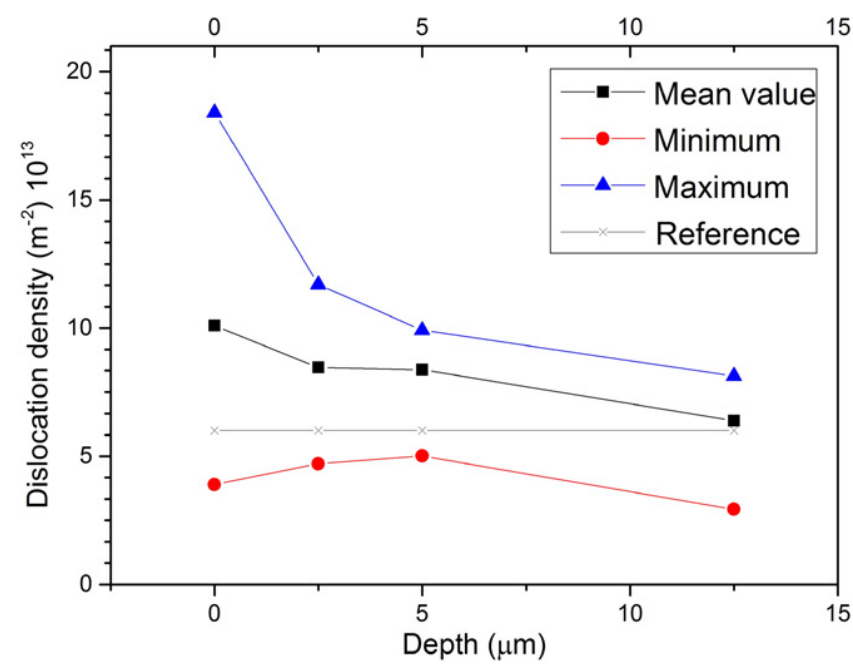

Figure 3. Average dislocation density as a function of depth from the exposed surface. The dislocation density in the reference un-exposed material is $6.5 \times 10^{13} \mathrm{~m}^{-2}$.

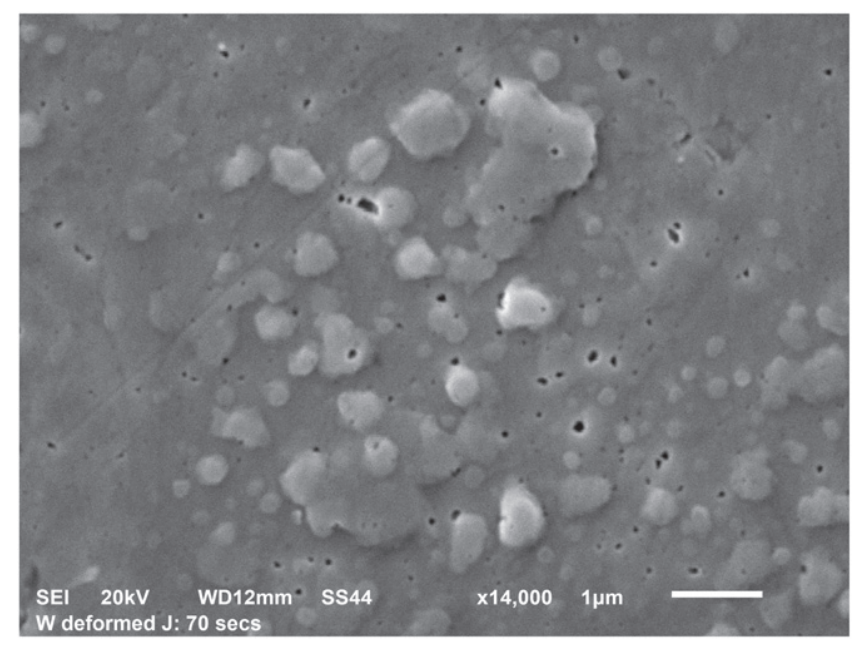

Figure 4. Blisters observed on the plasma exposed surface of the sample by SEM analysis.

\section{Discussion and conclusive remarks}

The apparent increase in the dislocation density in the subsurface region after the exposure is attributed here to the mechanical deformation resulting from the growth of bubbles and temperature gradient. The presence of growing bubbles is confirmed by the blisters observed on the surface of the same sample by SEM analysis. In the present experiment as well as in a similar recent experiment [23], blisters, particular to high dose exposure, were observed. The SEM micrograph of the blisters is shown on figure 4 and additional micrographs are attached as on line supplementary material available at (stacks.iop.org/PSTOP/T167/014030/mmedia). The present observation of dense dislocation networks proves that the nature of high dome blisters is related to extensive sub-surface plastic deformation. One can also note that the reduction of the dislocation density to the level of the reference value beyond a depth of $10 \mu \mathrm{m}$ correlates well with the strong gradient of the $D$ concentration retained after the high flux plasma exposure, as measured by NRA [3-6]. We would like to stress that the above observations are grounded by considerable statistics. For each layer, 10-15 TEM images were analyzed selecting grains with different orientation and size to ensure representativity of the results.

Secondly, numerous observations of edge dislocation loops point to the operation of the loop-punching mechanism or coalescence of self-interstitials, in both cases emitted as a result of $D$ bubble growth. Importantly, no edge dislocation loops were observed in the reference material, and the kinetic energy of impinging $D$ ions is too low to generate lattice defects. In our previous work, we already proved the presence of nanometric bubbles on dislocations in the same material and exposure conditions, but the exposure temperature was $470 \mathrm{~K}$ [13]. The size of the dislocation loops $(10-35 \mathrm{~nm})$, observed here at $620 \mathrm{~K}$, indirectly confirms the presence of $D$ bubbles in the same range of sizes. To our best knowledge, this is the first observation of the edge interstitial dislocation loops at conditions corresponding to low-energy plasma exposure. Previously both $a_{0} / 2\langle 111\rangle$ and $a_{0}\langle 100\rangle$ interstitial and vacancy loops were observed in $\mathrm{W}$ under high energy ion [24] and fast neutron irradiation [25], but as a result of collapse of the cascade region or by agglomeration of selfinterstitial defects.

Considering previously reported microstructural examinations, made after high-flux plasma exposure across the sample, [26] revealed the presence of $\mu \mathrm{m}$-size cavities extended along the grain boundary interfaces, thus eventually being flakes. Apparently, as soon as a bubble, nucleated on the grain boundary, reaches a critical size, it starts to emit half-loops thus extending its size along the grain boundary interface, thereby turning into a flake-shaped gas-filled cavity (such as reported in [27]). The already emitted half-loops are pushed away from the growing cavity which keeps on producing new half-loops. Overall, this process leads to the formation of dislocation tangles and networks, as observed here (see figure 2). Obviously, such microstructural evolution would significantly affect the mechanical properties of the thin sub-surface region, where the major change in dislocation density takes place. Our further step is therefore to perform nano-indentation mechanical testing to measure surface hardness and its evolution as a function of depth. Also, a similar study as here is currently undergoing for the reference non-deformed samples.

To summarize, the performed TEM investigation in $\mathrm{W}$ exposed to high flux plasma $\left(10^{24} \mathrm{D} \mathrm{m}^{-2} \mathrm{~s}^{-1}\right)$ at $620 \mathrm{~K}$ revealed that:

(i) Plasma exposure induces strong increase in the dislocation density in the sub-surface region up to $10^{14}$ or even $10^{15} \mathrm{~m}^{-2}$ in some local regions.

(ii) The exposure-induced dislocation microstructure vanishes beyond a depth of about $10 \mu \mathrm{m}$ from the top of the exposed surface, and the dislocation density becomes comparable to the reference one.

(iii) interstitial edge dislocation loops with Burgers vector $a_{0} / 2\langle 111\rangle$ and $a_{0}\langle 100\rangle$ were regularly observed within 
$6 \mu \mathrm{m}$ of the sub-surface region of the exposed samples, and were not observed in the as-deformed non-exposed material. The presence of these loops points to a coexistence of nanometric $D$ bubbles and sub-micron cavities with flake shapes. Bubbles are considered here to grow by loop punching mechanism, while the growth of flake-shaped cavities by half-loop emission results in the formation of surface blisters.

\section{Acknowledgments}

This work was supported by the European Commission and carried out within the framework of the Erasmus Mundus International Doctoral College in Fusion Science and Engineering (Fusion-DC). The work also partially supported by the funding received from the Euratom research and training programme 2014-2018 under grant agreement No 633053 (EUROfusion/Enabling Research programme). The views and opinions expressed herein do not necessarily reflect those of the European Commission.

\section{References}

[1] Pintsuk G 2012 Comprehensive Nucl. Mater. 4 551-81

[2] Loarte A et al 2003 J. Nucl. Mater. $313962-6$

[3] Alimov V K et al 2009 Phys. Scr. 2009014048

[4] Tanabe T 2014 Phys. Scr. 2014014044

[5] 't Hoen M H J, Tyburska-Pûschel B, Ertl K, Mayer M, Rapp J, Kleyn A W and Zeijlmans van Emmichoven P A 2012 Nucl. Fusion 52023008

[6] Alimov V K, Roth J and Mayer M 2005 J. Nucl. Mater. 337 619-23
[7] Alimov V K and Roth J 2007 Phys. Scr. 20076

[8] Shimada M et al 2015 Nucl. Fusion 55013008

[9] Sugiyama K et al 2011 Phys. Scr. 2011014033

[10] Sugiyama K et al 2014 Phys. Scr. 2014014043

[11] Khripunov B et al 2015 J. Nucl. Mater. 463 258-62

[12] Balden M et al 2014 J. Nucl. Mater. 452 248-56

[13] Terentyev D, Dubinko V, Bakaev A, Zayachuk Y, Van Renterghem W and Grigorev P 2014 Nucl. Fusion 54 042004

[14] Terentyev D, De Temmerman G, Minov B, Zayachuk Y, Lambrinou K, Morgan T W, Dubinko A, Bystrov K and Van Oost G 2015 Nucl. Fusion 55013007

[15] Terentyev D, De Temmerman G, Morgan T W, Zayachuk Y, Lambrinou K, Minov B, Dubinko A, Bystrov K and Van Oost G 2015 J. Appl. Phys. 117083302

[16] Pintsuk G and Uytdenhouwen I 2010 Int. J. Refract. Met. Hard Mater. 28 661-8

[17] Sheng H, Van Oost G, Zhurkin E, Terentyev D, Dubinko V I, Uytdenhouwen I and Vleugels J $2014 \mathrm{~J}$. Nucl. Mater. 444 214-9

[18] Hirsch P, Howie A, Nicholson R, Pashley D W and Whelan M J 1977 Microscopy of Thin Crystals (Malabar, FL: Krieger) p 422

[19] van Rooij G J et al 2007 Appl. Phys. Lett. 90121501

[20] De Temmerman G et al 2011 Nucl. Fusion 51073008

[21] Was G S 2007 Fundamentals of Radiation Materials Science: Metals and Alloys (Berlin: Springer)

[22] van der Meiden H, Al R, Barth C, Donee A, Engeln R and Goedheer W 2008 Rev. Sci. Instrum. 79013505

[23] Jia Y Z, De Temmerman G, Luo G N, Xu H Y, Li C, Fu B Q and Liu W 2015 J. Nucl. Mater. 457 213-9

[24] Yi X, Jenkins M L, Briceno M, Roberts S G, Zhou Z and Kirk M A 2013 Phil. Mag. 93 1715-38

[25] Tanno T, Fukuda M, Nogami S and Hasegawa A 2011 Mater. Trans. 52 1447-51

[26] Lindig S, Balden M, Alimov V K, Manhard A, Hoschen C, Hoschen T, Tyburska-Puschel B and Roth J 2011 Phys. Scr. 2011014039

[27] Balden M et al 2011 J. Nucl. Mater. 414 69-72 